\title{
ChemComm
}

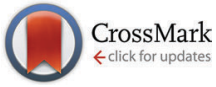

Cite this: Chem. Commun., 2016, 52,7826

Received 5th May 2016, Accepted 17th May 2016

DOI: $10.1039 / c 6 c c 03787 a$

www.rsc.org/chemcomm

\section{Mixed-linker approach in designing porous zirconium-based metal-organic frameworks with high hydrogen storage capacity $\dagger$}

\author{
Ayesha Naeem, ${ }^{a}$ Valeska P. Ting, ${ }^{\mathrm{b}}$ Ulrich Hintermair, ${ }^{c}$ Mi Tian, ${ }^{\mathrm{b}}$ Richard Telford, ${ }^{a}$ \\ Saaiba Halim, ${ }^{a}$ Harriott Nowell, ${ }^{d}$ Małgorzata Hotyńska, ${ }^{e}$ Simon J. Teat, ${ }^{f}$ \\ Ian J. Scowen ${ }^{g}$ and Sanjit Nayak ${ }^{\star a}$
}

Three highly porous Zr(iv)-based metal-organic frameworks, UBMOF-8, UBMOF-9, and UBMOF-31, were synthesized by using $2,2^{\prime}$-diamino4,4'-stilbenedicarboxylic acid, 4,4'-stilbenedicarboxylic acid, and combination of both linkers, respectively. The mixed-linker UBMOF-31 showed excellent hydrogen uptake of $4.9 \mathrm{wt} \%$ and high selectivity for adsorption of $\mathrm{CO}_{2}$ over $\mathrm{N}_{2}$ with high thermal stability and moderate water stability with permanent porosity and surface area of $2552 \mathrm{~m}^{2} \mathrm{~g}^{-1}$.

Hydrogen has gained enormous attention as a promising energy vector in renewable energy conversion schemes due to its environmentally friendly nature; it can be cleanly produced by electrolysis of water, and water is the main by-product of $\mathrm{H}_{2}$ combustion. ${ }^{1}$ However, especially for applications in automobiles, storage and transportation of hydrogen is a major challenge due to its very low boiling point and low volumetric density in gaseous form. ${ }^{2-4}$ Metal-organic frameworks (MOFs) with very high surface areas are promising candidates for tackling this problem by adsorptive storage of hydrogen to achieve higher hydrogen densities under acceptable conditions. ${ }^{5-8}$ Research in this area has indicated that this class of materials has the potential for meeting the systems' $\mathrm{H}_{2}$ storage capacity benchmark of $5.5 \mathrm{wt} \%$ set for 2017 by the US Department of Energy (DOE).$^{9}$

\footnotetext{
${ }^{a}$ School of Chemistry and Forensic Sciences, University of Bradford, Richmond Road, Bradford, West Yorkshire, BD7 1DP, UK. E-mail: s.nayak@bradford.ac.uk

${ }^{b}$ Department of Chemical Engineering, University of Bath, Claverton Down, Bath, BA2 7AY, UK

${ }^{c}$ Centre for Sustainable Chemical Technologies, University of Bath, Caverton Down, Bath, BA2 7AY, UK

${ }^{d}$ Diamond Light Source, Didcot, Oxon, OX11 ODE, UK

${ }^{e}$ Fachbereich Chemie and Wissenschaftliches Zentrum für Materialwissenschaften, Philipps Universität Marburg, Hans-Meerwein-Straße, 35043 Marburg, Germany

${ }^{f}$ Advanced Light Source, Lawrence Berkeley National Laboratory, Berkeley, CA 94720, USA

${ }^{g}$ School of Chemistry, University of Lincoln, Brayford Pool, Lincoln, Lincolnshire, LN6 7TS, UK

$\dagger$ Electronic supplementary information (ESI) available: Experimental details, single-crystal structure determination, materials characterization (IR, TGA, NMR), and details of gas sorption experiments. CCDC 1440758 and 1440759. For the ESI and crystallographic data in CIF or other electronic format see DOI: 10.1039/c6cc03787a
}

Despite the fact that a large number of MOFs have been studied for hydrogen storage properties, ${ }^{2,6,8,10,11}$ the problem of low thermal and water stabilities of many MOFs is a major issue for practical applications. ${ }^{12}$ Newly developed Zr-based MOFs with archetypical $\left[\mathrm{Zr}_{6} \mathrm{O}_{4}(\mathrm{OH})_{4}\left(\mathrm{CO}_{2}\right)\right]$ secondary building units (SBUs) are highly promising for this purpose, due to their exceptional thermal and water stabilities, ${ }^{13-16}$ and recent studies have shown that UiO-67 (UiO: University of Oslo) can attain up to $4.6 \mathrm{wt} \% \mathrm{H}_{2}$ storage at $3.8 \mathrm{MPa} .{ }^{14}$

Here we report three $\mathrm{Zr}(\mathrm{Iv})$-based MOFs using $4,4^{\prime}$-stilbenedicarboxylic acid and 2,2'-diamino-4,4'-stilbenedicarboxylic acid as linkers, with one of them synthesized using a non-traditional mixed-linker approach, showing one of the highest (up to $4.9 \mathrm{wt} \%$ ) hydrogen uptakes measured among the Zr-based MOFs reported to date. ${ }^{14,15,17,18}$ In addition, high selectivity of $\mathrm{CO}_{2}$ adsorption over nitrogen was also observed for UBMOF-31. Solvothermal reactions of $2,2^{\prime}$-diamino-4,4'-stilbenedicarboxylic acid $\left(\mathrm{DASDCAH}_{2}\right)$ and $4,4^{\prime}$-stilbenedicarboxylic acid $\left(\mathrm{SDCAH}_{2}\right)$ with $\mathrm{ZrCl}_{4}$ and benzoic acid (modulator) in a mixture of dimethylformamide (dmf) and $N$-methyl-2-pyrrolidone (NMP) $(5: 1, \mathrm{v} / \mathrm{v})$ produced $\left[\mathrm{Zr}_{6} \mathrm{O}_{4}(\mathrm{OH})_{4^{-}}\right.$ $\left.(\text { DASDCA })_{6}\right](\mathrm{PhCOOH})_{m}\left(\mathrm{dmf}_{x}\left(\mathrm{H}_{2} \mathrm{O}\right)_{y}(\mathrm{NMP})_{z} \quad(\mathrm{UBMOF}-8)\right.$ and $\left[\mathrm{Zr}_{6} \mathrm{O}_{4}(\mathrm{OH})_{4}(\mathrm{SDCA})_{6}\right](\mathrm{PhCOOH})_{n}\left(\mathrm{dmf}_{p}\left(\mathrm{H}_{2} \mathrm{O}\right)_{q}(\mathrm{NMP})_{r}\right.$ (UBMOF-9), respectively, where UBMOF refers to University of Bradford Metal-Organic Framework (Fig. 1). ${ }^{19}$ The actual amount of solvent in the lattice varies, and it was not determined experimentally for these compounds. Both these syntheses resulted in crystals suitable for structural analysis by single crystal X-ray diffraction. Both these MOFs are formed of octahedral $\left[\mathrm{Zr}_{6} \mathrm{O}_{4}(\mathrm{OH})_{4}\left(\mathrm{CO}_{2}\right)\right]$ cluster units connected by twelve DASDCA or SDCA linkers similar to UiO-66. ${ }^{13}$ Use of these longer linkers results in large diagonal cage dimensions of approximately $25 \AA$ and equilateral triangular faces with side lengths of $17.7 \AA$ (Fig. 1 and Fig. S3.1 in ESI $\dagger$ ). Structural analyses using the OLEX-2 program suite indicate solvent accessible volumes of $71.9 \%$ and $75.3 \%$ for UBMOF- 8 and UBMOF-9, respectively, with a probe of radius $1.2 \AA^{20}$

Unlike UBMOF-9, UBMOF-8 did not produce a phase pure material despite extensive efforts to optimise the synthetic conditions. An unidentified amorphous phase was present alongside 
<smiles>Nc1cc(C(=O)O)ccc1/C=C/c1ccc(C(=O)O)cc1N</smiles>

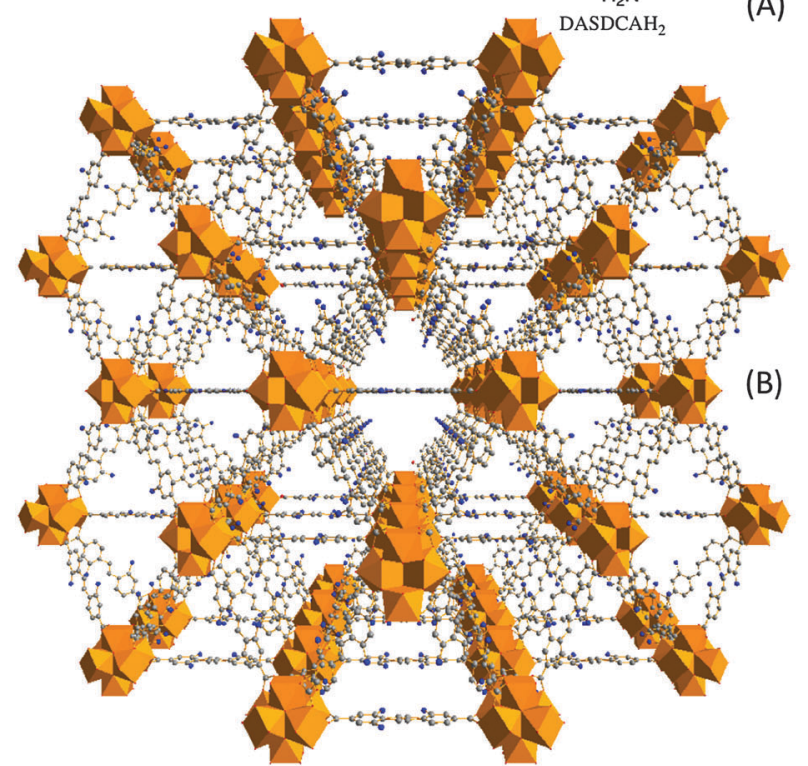

(B)

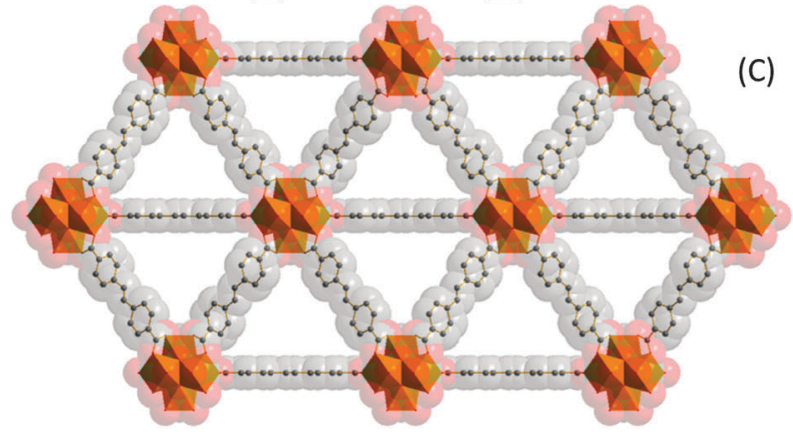

Fig. 1 (A) The two linkers, 2,2'-diamino-4,4'-stilbenedicarboxylic acid $\left(\right.$ DASDCAH $\left.{ }_{2}\right)$ and $4,4^{\prime}$-stilbenedicarboxylic acid $\left(\mathrm{SDCAH}_{2}\right)$, used to synthesise UBMOF-8 and UBMOF-9, respectively. (B) Central projection view of UBMOF-8 along the [101] direction. (C) View of UBMOF-8 along [101] direction with $\left[\mathrm{Zr}_{6} \mathrm{O}_{8}\right]$ polyhedral nodes shown in orange to demonstrate the three-dimensional porosity of the structures. The hydrogen atoms and the disordered carbon and nitrogen atoms are excluded for clarity.

the crystalline material for UBMOF-8 (Fig. 2), as evidenced by a noticeable amorphous halo in the PXRD pattern (Fig. 3A). As an alternate route to access the pure isostructural MOF with amino groups, we took advantage of the similar coordination behaviours of both linkers and experimentally optimised the ratio of the two linkers. This mixed linker approach resulted in a crystalline phase pure material (UBMOF-31) isostructural to UBMOF-8 and UBMOF-9 when DASDCAH ${ }_{2}$ and $\mathrm{SDCAH}_{2}$ were used in a 1:2.5 molar ratio. The empirical formula for desolvated UBMOF-31, $\left[\mathrm{Zr}_{6} \mathrm{O}_{4}(\mathrm{OH})_{4}(\mathrm{DASDCA})_{1.4}(\mathrm{SDCA})_{4.6}\right](\mathrm{PhCOOH})_{0.78}$, was determined from the combination of data obtained from elemental analysis, thermogravimetric analysis (TGA) and NMR spectroscopy (see the ESI $\dagger$ ).

The calculated and measured PXRD patterns match closely, suggesting a phase pure crystalline material for the pristine

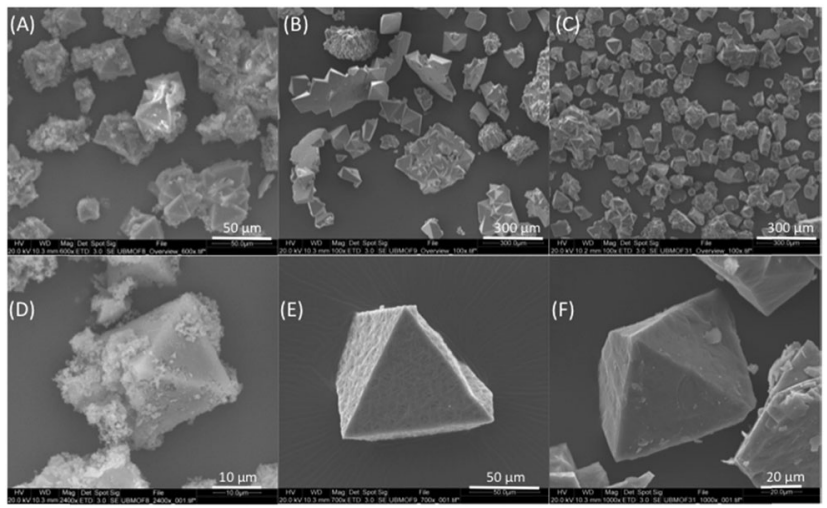

Fig. 2 SEM images of bulk phases of (A) UBMOF-8, (B) UBMOF-9, and (C) UBMOF-31, and their closeup views $D$, E, and F, respectively.

(A)

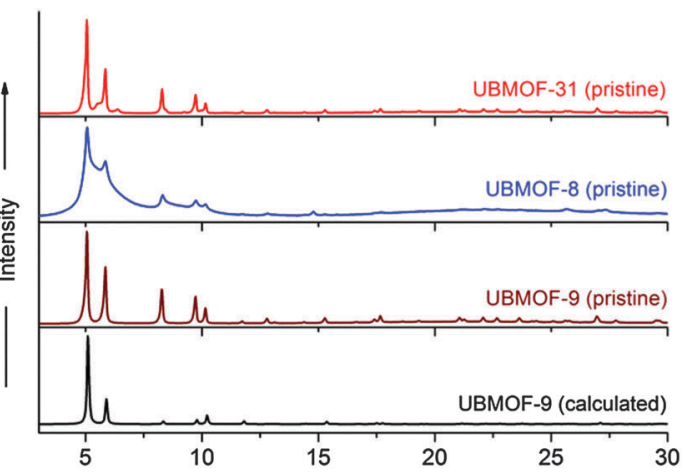

(B)

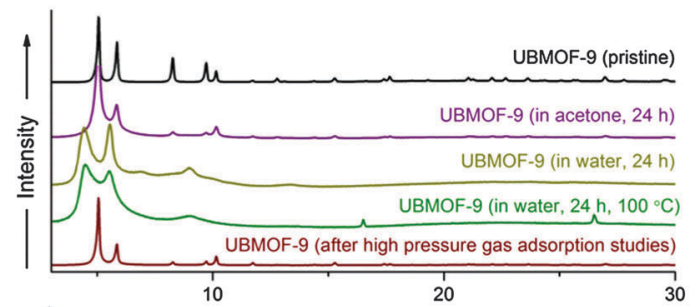

(C)

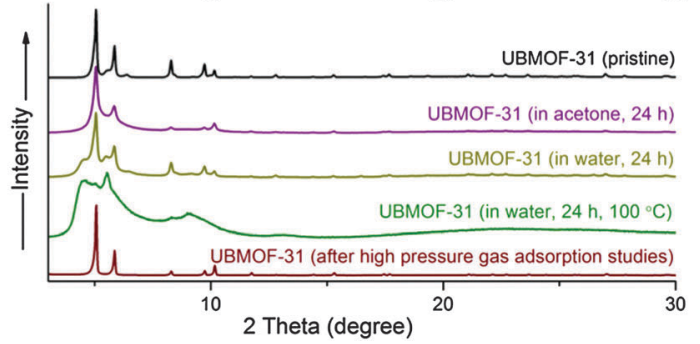

Fig. 3 (A) Calculated PXRD pattern for UBMOF-9 and measured PXRD patterns for pristine UBMOF-8, UBMOF- 9 , and UBMOF-31 suggesting the phase-pure bulk material of UBMOF 9 and UBMOF-31. (B and C) Comparison of the PXRD patterns of UBMOF- 9 and UBMOF-31 treated under different conditions.

sample UBMOF-9 (Fig. 3B). The single crystals of UBMOF-8 produced along with powdery amorphous materials can be observed in the SEM images (see the ESI $\dagger$ ). The discrepancy of elemental analysis (see the ESI $\dagger$ ) for UBMOF-8 further suggests the presence of impurity in the bulk material. The residual amounts of modulator (PhCOOH) inside the MOFs were estimated for the solvent exchanged and dried samples (see the ESI $\dagger$ ). In the IR spectra, 
the presence of $\mathrm{C}=\mathrm{O}$ stretching frequency $\left(1685 \mathrm{~cm}^{-1}\right)$ for noncoordinate benzoic acid indicates their origin as guest molecules, not from defects. The flexibility of the linkers possibly plays a role in minimizing the defects for this class of MOFs, as was observed for another family of isostructural Zr-based MOFs with varied flexibility. ${ }^{21}$ In addition, the presence of extensive disorder in the crystal structures restricts any further investigation on the accurate determination of defects in these materials. ${ }^{22}$

It is evident from the literature that the presence of amino groups on the linkers facilitates hydrogen adsorption in MOFs. ${ }^{23}$ This motivated us to explore an alternate route to produce a phase pure amino functionalized isostructural MOF by a mixed-linker approach with controlled use of both linkers to synthesize UBMOF31 with the DASDCAH ${ }_{2}: \mathrm{SDCAH}_{2}$ ratio of 1.4 : 4.6. A further increase of $\mathrm{DASDCAH}_{2}$ resulted in amorphous impurity as originally observed for UBMOF-8. The infrared spectra (see the ESI $\dagger$ ) of all three fresh compounds indicate the presence of a large amount of dmf with an intense peak at $1654 \mathrm{~cm}^{-1}$, which diminished upon washing with acetone and activation by supercritical $\mathrm{CO}_{2}$ during gas adsorption studies. The shoulder peaks around $3670 \mathrm{~cm}^{-1}$ possibly originate from the $\mathrm{OH}$ groups as suggested in the literature. ${ }^{24}$ Thermal stabilities of the three MOFs were studied by TGA in air (see the ESI $\dagger$ ) at a heating ramp of $5{ }^{\circ} \mathrm{C}$ per minute. All three freshly prepared, air-dried MOFs show a large initial drop in weight (40-50\%) due to solvent loss, followed by a stable plateau until they decompose at approximately $494{ }^{\circ} \mathrm{C}$ (UBMOF-8), $522{ }^{\circ} \mathrm{C}$ (UBMOF-9), and $508{ }^{\circ} \mathrm{C}$ (UBMOF-31), indicating thermal stabilities comparable with UiO-66. ${ }^{13,14}$ TGAs of de-solvated and vacuum treated samples were carried out to estimate the linker ratios for UBMOF-31 and the guest modulator, in combination with elemental analysis and NMR spectroscopy (see the ESI $\dagger$ ). The PXRD pattern in Fig. 3A suggests that UBMOF-31 is phase pure and isostructural to UBMOF-8 and UBMOF-9 as expected. PXRD analyses of the samples revealed the stability of UBMOF-9 and UBMOF-31 under different conditions as shown in Fig. 3. Both these materials retain their original structures when treated with acetone for 24 hours at $20{ }^{\circ} \mathrm{C}$, after activation using supercritical $\mathrm{CO}_{2}$, and after high-pressure adsorption studies with $\mathrm{N}_{2}, \mathrm{H}_{2}$, and $\mathrm{CO}_{2}$. When treated with water at $20{ }^{\circ} \mathrm{C}$ for 24 hours, both (UBMOF-8 and UBMOF-31) retain their shiny crystalline morphology to some extent as visually inspected (see the ESI $\dagger$ ) and evidenced by PXRD (Fig. 3), with a small shift in $2 \theta$ for the low-angle peaks for UBMOF-9. However, UBMOF-31 mostly retains its original PXRD pattern, indicating better water stability compared to UBMOF-9. The hydrothermal treatment $\left(100^{\circ} \mathrm{C}\right)$ of both the MOFs over 24 hours resulted in broadening of the low-angle peaks leaving no visible high-angle peaks, indicating significant loss of crystallinity of the materials. The surface areas of the materials were determined by Brunauer-Emmett-Teller (BET) analysis with $\mathrm{N}_{2}$ at $77 \mathrm{~K}$ using a Micromeritics 3-Flex volumetric gas sorption analyser $\left(P / P_{\mathrm{o}}\right.$ range: 0.05-0.3) following the British Standard guidelines. ${ }^{25}$ A sample of UBMOF-9 that had been solvent-exchanged with acetone and degassed at $150{ }^{\circ} \mathrm{C}$ for 8 hours under dynamic high vacuum $\left(10^{-7}\right.$ mbar) prior to analysis displayed a surface area of $1169 \mathrm{~m}^{2} \mathrm{~g}^{-1}$. In order to access the true intrinsic porosity of these materials, the samples were solvent exchanged and subsequently subjected to supercritical $\mathrm{CO}_{2}\left(\mathrm{scCO}_{2}\right)$ extraction. ${ }^{26,27}$
The $\mathrm{scCO}_{2}$-activated samples showed BET surface areas of $2667 \mathrm{~m}^{2} \mathrm{~g}^{-1}$ and $2552 \mathrm{~m}^{2} \mathrm{~g}^{-1}$ for UBMOF-9 and UBMOF-31, respectively, more than twice the value obtained for the thermally dried samples. High pressure hydrogen sorption analysis was carried out for both $\mathrm{ScCO}_{2}$-activated MOFs. A maximum loading of $\sim 4 \mathrm{wt} \%$ was observed for UBMOF-9 at a measured range of $13 \mathrm{MPa}$ without reaching saturation (Fig. 4A). In contrast, UBMOF-31 attains a maximum uptake of $4.9 \mathrm{wt} \%$ at $4.6 \mathrm{MPa}$ and $77 \mathrm{~K}$ (Fig. $4 \mathrm{~A}$ ), making it one of the best Zr-based MOFs for hydrogen storage capacity to date. ${ }^{14}$ The presence of a maximum observed for UBMOF-31 is usual and expected where the surface interacts positively for the adsorption process, and the adsorption efficiency drops after covering the surface with the first layer of guest molecules. ${ }^{8,28}$ For a brief overview and comparison of hydrogen uptakes by different Zr-based MOFs, see Table S8.1 in the ESI. $\uparrow$ The increased hydrogen storage capacity of UBMOF-31 can be explained by attractive interactions between the $\mathrm{H}_{2}$ molecules and the amino substituted benzene rings as suggested by theoretical calculations. ${ }^{23}$

Although there are a large number of MOFs with high selectivity towards $\mathrm{CO}_{2}$ adsorption, only a few of them are stable under air and moisture, restricting their possible applications in $\mathrm{CO}_{2}$ capture and separation. ${ }^{12}$ In addition, the presence of amino groups on the
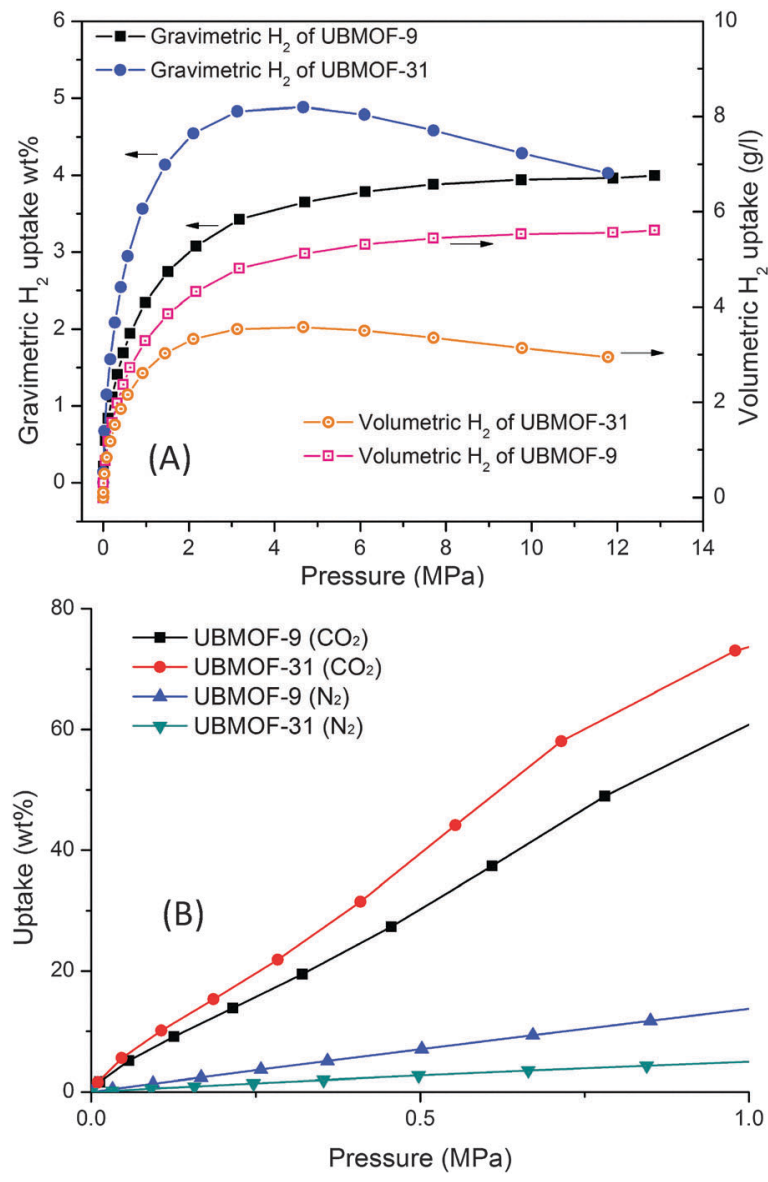

Fig. 4 (A) High-pressure hydrogen adsorption studies (gravimetric and volumetric) of UBMOF-9 and UBMOF-31. (B) Study of $\mathrm{CO}_{2}$ adsorption and $\mathrm{N}_{2}$ adsorption showing greater affinity of UBMOF-31 for $\mathrm{CO}_{2}$ over $\mathrm{N}_{2}$, compared to UBMOF-9 at $1 \mathrm{MPa}$ and $0{ }^{\circ} \mathrm{C}$. 
linkers often facilitates $\mathrm{CO}_{2}$ adsorption by the chemisorption process. The presence of both of these features motivated us to further study $\mathrm{CO}_{2}$ adsorption properties of these MOFs. ${ }^{29}$ The $\mathrm{CO}_{2}$ uptake was recorded to be $8 \mathrm{wt} \%$ and $8.6 \mathrm{wt} \%$ for UBMOF-9 and UBMOF-31, respectively, at $0{ }^{\circ} \mathrm{C}$ and 1 bar pressure. Slightly lower uptakes of $2.06 \mathrm{wt} \%$ and $2.86 \mathrm{wt} \%$ were observed for UBMOF-9 and UBMOF-31, respectively, at $20{ }^{\circ} \mathrm{C}$ and 1 bar pressure (Fig. S8.9 in the ESI $\dagger$ ). Adsorption of $\mathrm{CO}_{2}$ under high pressure was also studied. Notably UBMOF-31 shows much greater affinity towards $\mathrm{CO}_{2}$ reaching $73 \mathrm{wt} \%$ compared to $63 \mathrm{wt} \%$ of UBMOF-9 at $1 \mathrm{MPa}$ (Fig. 4B). ${ }^{29}$ However, at a higher pressure, the $\mathrm{CO}_{2}$ uptake for UBMOF-9 exceeds the value for UBMOF-31 (see the ESI $\dagger$ ). Therefore, the first part of the adsorption isotherm is most likely to be dominated by chemisorption at the amine sites and the latter part by physisorption on the internal surface of the highly porous framework. Consistent with this interpretation, a high selectivity towards $\mathrm{CO}_{2}$ adsorption over nitrogen was observed $(15: 1)$ for UBMOF-31 in the chemisorption regime at $0{ }^{\circ} \mathrm{C}$ and $1 \mathrm{MPa}$, making it a promising material for $\mathrm{CO}_{2}$ capture and separation.

In summary, we report three new Zr-based MOFs, UBMOF-8, UBMOF-9, and UBMOF-31, with the latter synthesized using a mixed-linker strategy. Because of the presence of amino groups in UBMOF-31, it shows enhanced $\mathrm{H}_{2}$ adsorption capacity with $4.9 \mathrm{wt} \%$ of loading at $4.6 \mathrm{MPa}$, one of the highest uptakes for Zr-based MOFs reported to date. In addition, UBMOF-31 shows high affinity towards $\mathrm{CO}_{2}$ adsorption over nitrogen, with a selectivity of $15: 1$ at $0{ }^{\circ} \mathrm{C}$ under $1 \mathrm{MPa}$ pressure. In addition to its exceptional hydrogen uptake and selectivity towards $\mathrm{CO}_{2}$ adsorption, UBMOF-31 shows good hydrolytic stability, making it a promising candidate for further studies and practical applications for gas storage and separation. We are currently working on synthesizing phase pure UBMOF-8 and isostructural materials with an increased proportion of the $\mathrm{DASDCAH}_{2}$ linker to systematically investigate the effect of amino groups on the hydrogen storage capacity of this family of Zr-based MOFs.

SN thanks the Royal Society of Chemistry for financial support. VPT and UH thank the University of Bath for funding through a Prize Research Fellowship and Whorrod Research Fellowship, respectively. MT thanks support from the H2FC SUPERGEN Hub (EP/E040071/1). The Advanced Light Source is supported by the Director, Office of Science, Office of Basic Energy Sciences, of the U.S. Department of Energy under Contract No. DE-AC02-05CH11231.

\section{References}

1 A. Bocarsly and D. M. P. Mingos, Structure and Bonding (Fuel Cells and Hydrogen Storage), Springer, Heidelberg, Germany, 2011.

2 M. P. Suh, H. J. Park, T. K. Prasad and D. W. Lim, Chem. Rev., 2012, 112, 782-835.

3 M. Dincǎ and J. R. Long, Angew. Chem., Int. Ed., 2008, 47, 6766-6779.
4 C. Stockford, N. Brandon, J. Irvine, T. Mays, I. Metcalfe, D. Book, P. Ekins, A. Kucernak, V. Molkov, R. Steinberger-Wilckens, N. Shah, P. Dodds, C. Dueso, S. Samsatli and C. Thompson, Int. J. Hydrogen Energy, 2015, 40, 5534-5543.

5 J. L. C. Rowsell and O. M. Yaghi, Angew. Chem., Int. Ed., 2005, 44, 4670-4679.

6 H. W. Langmi, J. Ren, B. North, M. Mathe and D. Bessarabov, Electrochim. Acta, 2014, 128, 368-392.

7 S. S. Han, J. L. Mendoza-Cortes and W. A. Goddard Iii, Chem. Soc. Rev., 2009, 38, 1460-1476.

8 L. J. Murray, M. Dinca and J. R. Long, Chem. Soc. Rev., 2009, 38, 1294-1314.

9 See the hydrogen storage target set by DOE in the United States http://energy.gov/eere/fuelcells/downloads/fuel-cell-technologies-officemulti-year-research-development-and-22.

10 M. Dincǎ, A. Dailly, Y. Liu, C. M. Brown, D. A. Neumann and J. R. Long, J. Am. Chem. Soc., 2006, 128, 16876-16883.

11 Z. Wang, K. K. Tanabe and S. M. Cohen, Chem. - Eur. J., 2010, 16, 212-217.

12 S. S. Kaye, A. Dailly, O. M. Yaghi and J. R. Long, J. Am. Chem. Soc., 2007, 129, 14176-14177.

13 J. H. Cavka, S. Jakobsen, U. Olsbye, N. Guillou, C. Lamberti, S. Bordiga and K. P. Lillerud, J. Am. Chem. Soc., 2008, 130, 13850-13851.

14 S. Chavan, J. G. Vitillo, D. Gianolio, O. Zavorotynska, B. Civalleri, S. Jakobsen, M. H. Nilsen, L. Valenzano, C. Lamberti, K. P. Lillerud and S. Bordiga, Phys. Chem. Chem. Phys., 2012, 14, 1614-1626.

15 L. Li, S. Tang, C. Wang, X. Lv, M. Jiang, H. Wu and X. Zhao, Chem. Commun., 2014, 50, 2304-2307.

16 Y. Han, H. Xu, Y. Liu, H. Li, H. Hou, Y. Fan and S. R. Batten, Chem. - Eur. J., 2012, 18, 13954-13958.

17 J. Ren, N. M. Musyoka, H. W. Langmi, B. C. North, M. Mathe, X. Kang and S. Liao, Int. J. Hydrogen Energy, 2015, 40, 10542-10546.

18 J. Ren, H. W. Langmi, B. C. North, M. Mathe and D. Bessarabov, Int. J. Hydrogen Energy, 2014, 39, 890-895.

19 Isostructural compound to UBMOF-9 reported during reviewing process: R. J. Marshall, C. L. Hobday, C. F. Murphie, S. L. Griffin, C. A. Morrison, S. A. Moggach and R. S. Forgan, J. Mater. Chem. A, 2016, 4, 6955-6963; and in an MSc thesis: http://handle.ncl.edu.tw/ 11296/ndltd/48318579606892167335.

20 O. V. Dolomanov, A. J. Blake, N. R. Champness and M. Schroder, J. Appl. Crystallogr., 2003, 36, 1283-1284.

21 S. B. Kalidindi, S. Nayak, M. E. Briggs, S. Jansat, A. P. Katsoulidis, G. J. Miller, J. E. Warren, D. Antypov, F. Corà, B. Slater, M. R. Prestly, C. Martí-Gastaldo and M. J. Rosseinsky, Angew. Chem., Int. Ed., 2015, 54, 221-226.

22 C. A. Trickett, K. J. Gagnon, S. Lee, F. Gándara, H.-B. Bürgi and O. M. Yaghi, Angew. Chem., Int. Ed., 2015, 54, 11162-11167.

23 R. C. Lochan and M. Head-Gordon, Phys. Chem. Chem. Phys., 2006, 8, 1357-1370.

24 L. Valenzano, B. Civalleri, S. Chavan, S. Bordiga, M. H. Nilsen, S. Jakobsen, K. P. Lillerud and C. Lamberti, Chem. Mater., 2011, 23, 1700-1718.

25 Determination of the specific surface area of powders - Part 1: BET method of gas adsorption for solids (including porous materials): BS 4359-1:1996, ISO 9277:1995.

26 Aerogels Handbook, Springer-Verlag, New York, 2011.

27 U. Hintermair, C. Roosen, M. Kaever, H. Kronenberg, R. Thelen, S. Aey, W. Leitner and L. Greiner, Org. Process Res. Dev., 2011, 15, $1275-1280$

28 N. Bimbo, J. E. Sharpe, V. P. Ting, A. Noguera-Díaz and T. J. Mays, Adsorption, 2013, 20, 373-384.

29 T. M. McDonald, D. M. D'Alessandro, R. Krishna and J. R. Long, Chem. Sci., 2011, 2, 2022-2028. 